\title{
Ambulatory extracorporeal membrane oxygenation as a bridge to cardiac transplant: A step in the right direction?
}

\author{
Harold M. Burkhart, MD, ${ }^{\mathrm{a}}$ Jess L. Thompson, $\mathrm{MD},{ }^{\mathrm{a}}$ and Christopher E. Mascio, $\mathrm{MD}^{\mathrm{b}}$
}

\footnotetext{
From the a Division of Cardiovascular and Thoracic Surgery, University of Oklahoma Health Sciences Center, Oklahoma City, Okla; and the bivision of Pediatric Cardiothoracic Surgery, Children's Hospital of Philadelphia, Perelman School of Medicine, University of Pennsylvania, Philadelphia, Pa.

Disclosures: C.E.M. is a clinical consultant for HeartWare. All other authors have nothing to disclose with regard to commercial support.

Received for publication March 11,2018; accepted for publication March 19, 2018; available ahead of print April $11,2018$.

Address for reprints: Harold M. Burkhart, MD, Division of Cardiovascular and Thoracic Surgery, University of Oklahoma Health Sciences Center, PO Box 26901, WP-2230, Oklahoma City, OK 73105 (E-mail: Harold-burkhart@ouhsc.edu).

J Thorac Cardiovasc Surg 2018;156:e11-2

$0022-5223 / \$ 36.00$

Copyright (C) 2018 by The American Association for Thoracic Surgery

https://doi.org/10.1016/j.jtcvs.2018.03.056
}

Mechanical circulatory support for cardiac failure is a quickly evolving discipline. Extracorporeal membrane oxygenation (ECMO) has typically been used to rescue patients with acute cardiac failure because it can be instituted rapidly with current reliable peripheral cannulation techniques and it affords the caregivers more time to formulate a definitive plan. Commonly, patients on ECMO support have been considered in too unstable condition to participate in active physical therapy because of concerns regarding cannula dislodgment and these patients' need for sedation. When ambulatory ECMO is possible, it can be associated with improved rates of return to independent functioning, decreased rates of delirium, shorter durations of mechanical ventilation, and shorter lengths of stay in the intensive care unit and hospital.

In this issue of the Journal, Shudo and colleagues ${ }^{2}$ present the case of an adolescent, obese male patient with idiopathic cardiomyopathy who was supported with ambulatory venoarterial ECMO as a bridge to cardiac transplant. Initially, the patient had peripheral cannulation; however, perhaps not surprisingly given his obesity, ECMO flows were inadequate to stave off end-organ malperfusion. He therefore had central cannulation performed, with tunneling of the cannulas through the skin to allowing the sternum to be closed primarily. With improved flow, the patient's kidneys and liver recovered while he remained supported on venoarterial ECMO for 96 days until cardiac transplant. Remarkably, the patient was extubated on ECMO day 9 and then engaged in physical rehabilitation, including ambulation. While the patient was on venoarterial ECMO support, he was able to shed about $35 \mathrm{~kg}$, reducing his body mass index from 43.9 to $32.5 \mathrm{~kg} / \mathrm{m}^{2}$. The fact that the patient was able to improve his cardiac transplant risk profile significantly while on central, ambulatory venoarterial ECMO support is the notable point of this case.

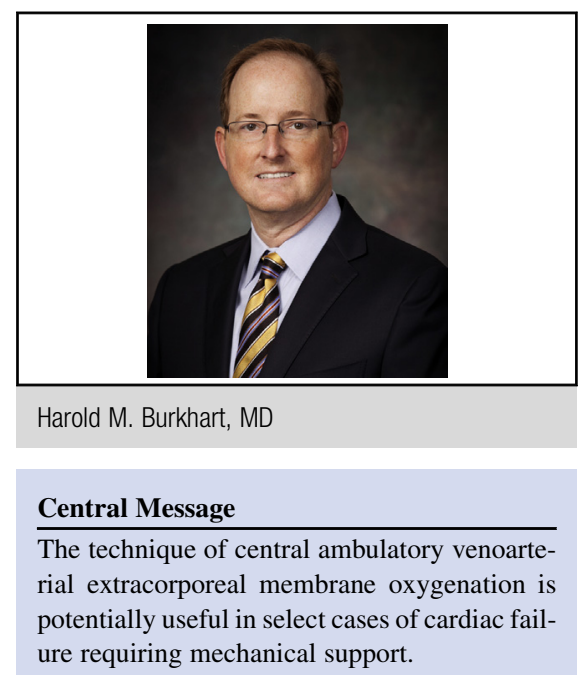

See Article page e7.

Despite the favorable outcome of this case, the enthusiasm for ambulatory, venoarterial ECMO as a bridge to heart transplant must be tempered. Currently, the standard support for bridge to transplant is an implantable, durable ventricular assist device (VAD). The use of ECMO as a direct bridge to heart transplant is associated with poor outcomes. Fukuhara and colleagues ${ }^{3}$ reported that the use of ECMO as a bridge to transplant was associated with higher early and midterm mortalities. This was especially true for patients with a high model for end-stage liver disease excluding international normalized ratio (MELD-XI) score, for whom mortality at 3 years was greater than $50 \%$. Jeewa and associates, ${ }^{4}$ from the Hospital for Sick Children in Toronto, reported their experience with ECMO versus VAD as a bridge to transplant in the pediatric population. They noted that patients requiring mechanical support had a high waitlist mortality overall, but the ability to transition to a durable VAD was associated with a lower waitlist mortality and a higher rate of hospital discharge.

In conclusion, the use of a VAD as a bridge to cardiac transplant remains the favored pathway for most patients with cardiac failure. Improved quality of life, including ease of ambulation, lower risk of cannula mishaps, and avoidance of an oxygenator in most cases, makes the VAD the preferred choice. That being said, there are scenarios, such as a hostile chest, difficult body habitus, and concerns for blood loss and sensitization, that may support continuation of central venoarterial ECMO rather than transition to a more durable 
VAD. In addition, the techniques reported by Shudo and colleagues ${ }^{2}$ may be of particular use in the patient with myocarditis who needs mechanical support with central cannulation and cardiac decompression as a bridge to recovery.

\section{References}

1. Lehr CJ, Zaas DW, Cheifetz IM, Turner DA. Ambulatory extracorporeal membrane oxygenation as a bridge to lung transplantation: walking while waiting. Chest. 2015;147:1213-8.
2. Shudo Y, Wang H, Ha RV, Hayes AD, Woo YJ. Heart transplant after profoundly extended ambulatory central venoarterial extracorporeal membrane oxygenation. J Thorac Cardiovasc Surg. 2018;156:e7-9.

3. Fukuhara S, Takeda K, Kurlansky PA, Naka Y, Takayama H. Extracorporeal membrane oxygenation as a direct bridge to heart transplantation in adults. $J$ Thorac Cardiovasc Surg. 2018;155:1607-18.e6.

4. Jeewa A, Manlhiot C, McCrindle BW, Van Arsdell G, Humpl T, Dipchand AI. Outcomes with ventricular assist device versus extracorporeal membrane oxygenation as a bridge to pediatric heart transplantation. Artif Organs. 2010;34:1087-91. 